doi: $10.1017 / S 1092852912000132$

\title{
Could Lorazepam Be More Effective In Alcohol Withdrawal Than Other Benzodiazepines?
}

\author{
Sabine Pompéia, BS, Vania D'Almeida, BS, and Sergio Tufik, MD
}

\section{$\underline{\text { Return }}$}

Ms. Pompéia and Ms. D'Almeida are lecturers and Dr. Tufik is professor in the Department of Psychobiology, Universidade Federal de São Paulo (UNIFESP), in São Paulo, Brazil.

Faculty Disclosures: The authors report no affiliation with or financial interest in any organization that might pose a conflict of interest. Their work is financed by Associação Fundo de Incentivo à Psicofarmacologia (AFIP; www.afip.br) and Fundação de Amparo á Pesquisa do Estado de São Paulo (FAPESP; www.fapesp.br), and they receive research grants from Conselho Nacional de Desenvolvimento Científico e Tecnológico (CNPq; www.cnpq.br). All of the above are non-profit organizations that sponsor research in Brazil.

Submitted for publication: October 24, 2009; Accepted for publication: April 8, 2010; First published online: January 1, 2011.

Please direct all correspondence to: Sabine Pompéia, R. Napoleão de Barros, 925. CEP: 04024-002, São Paulo, SP, Brazil. Tel: 55-11-2149-0155, Fax: 55-11-55725092; E-mail: spompeia@gmail.com.

\section{To the Editor:}

We would like to comment on a paper by Kahn and colleagues ${ }^{1}$ which presented a case of alcohol withdrawal requiring very high lorazepam doses. Lorazepam is often considered the drug of choice in these cases. The reasons cited in the literature include that lorazepam is able to reduce alcohol withdrawal symptoms and that because it undergoes glucuronidation, ${ }^{2}$ it is adequate for treatment of patients with liver disease or in those with unknown liver function status. ${ }^{3}$ However, there is a dearth of well-controlled studies which compared the efficacy of this benzodiazepine in relation to other drugs in its class. Hence, current scientific knowledge does not permit the determination of the advantages 
in using lorazepam for treating alcohol withdrawal in comparison to other benzodiazepines.

Here we argue that it is quite possible that lorazepam administration differs from that of other classic benzodiazepines in alcohol withdrawal because this drug has an atypical effects profile. ${ }^{4,5}$ Lorazepam has been shown to lead to different effects when compared to other benzodiazepines in animal discrimination studies, ${ }^{6,7}$ human implicit memory, ${ }^{8}$ electroencephalogram fast activity ${ }^{9}$ short latency afferent inhibition, ${ }^{10}$ visual perception, ${ }^{11,12}$ and event-related potentials. This occurred even when the doses of lorazepam and of the other benzodiazepine to which it was compared were equated following strict criteria. ${ }^{13}$ The medications also presented opposite rapid eye movement (REM) sleep effects in different mice strains while leading to equivalent changes in non-REM sleep. ${ }^{14}$

The reason for the difference in effects of lorazepam and other benzodiazepines is unclear. We have previously suggested that the most convincing justification for lorazepam's atypical effects is that it may display specific binding profiles to as yet uncharacterized receptors, since this has proven true for drugs that have qualitative different effects from others in their class. ${ }^{4,5}$ It is thus possible that lorazepam may in some way elicit specific effects in alcohol withdrawal that are not verified with other benzodiazepines.

In addition to the mechanisms well discussed by Kahn and colleagues ${ }^{1}$ by which benzodiazepines have positive action in alcohol withdrawal, these drugs may be effective in part due to their capacity to reduce homocysteine, ${ }^{15}$ elevated levels of which are considered a risk factor for the occurrence of alcohol withdrawal seizures. ${ }^{16,17}$ If this reduction is confirmed after repeated dosing in actively drinking patients, it should be considered that benzodiazepines may be especially efficacious in treating those with hyperhomocysteinemia. Furthermore, different levels of this amino acid may explain the vastly different doses of benzodiazepines needed to treat alcohol withdrawal in different individuals as shown in the article by Kahn and colleagues. ${ }^{1}$

Further studies are needed to determine whether lorazepam has the same profile in the treatment of alcohol withdrawal syndrome as other benzodiazepines, since this drug has been shown to have an atypical effects profile. ${ }^{18}$ Also, part of the effectiveness of benzodiazepines, including lorazepam, in alcohol withdrawal may stem from their capacity 
to decrease homocysteine by an as yet unknown mechanism that should be investigated further in order to better treat this syndrome.

Sincerely,

Sabine Pompéia, BS

Vania D'Almeida, BS

Sergio Tufik, MD

\section{References}

1. Kahn DR, Barnhorst AV, Bourgeois JA. A case of alcohol withdrawal requiring $1,600 \mathrm{mg}$ of lorazepam in 24 hours. CNS Spectr. 2009;14(7):385-389.

2. Bird RD, Makela EH. Alcohol withdrawal: what is the benzodiazepine of choice? Ann Pharmacother.1994;28(1):67-71.

3. Kumar CN, Andrade C, Murthy P. A randomized, double-blind comparison of lorazepam and chlordiazepoxide in patients with uncomplicated alcohol withdrawal. J Stud Alcohol Drugs. 2009;70(3):467474.

4. Pompéia S, Bueno OFA, Tufik S. Lorazepam should no longer be used as a prototypical benzodiazepine. Psychopharmacology. 2003b;169(2):211-212.

5. Pompéia S, Manzano GM, Tufik S, Bueno OF. What makes lorazepam different from other benzodiazepines? J Physiol. 2005;569(Pt 2):709.

6. Ator NA, Griffiths RR. Selectivity in the generalization profile in baboons trained to discriminate lorazepam: benzodiazepines, barbiturates and other sedative/anxiolytics. J Pharmacol Exp Ther. 1997;282(3):14421457.

7. Ator NA, Kautz MA. Differentiating benzodiazepine- and barbituratelike discriminative stimulus effects of lorazepam, diazepam, pentobarbital, imidazenil and zaleplon in two- versus three-lever procedures. Behav Pharmacol. 2000;11(1):1-14.

8. Pompéia S, Bueno OFA, Galduróz JC, Tufik S. Stem-completion tasks (indirect, direct inclusion and exclusion) are differently affected by equipotent doses of lorazepam and flunitrazepam. Hum Psychopharmacol. 2003a; 18(7):541-549.

9. Itil T, Shapiro $D$, Itil $K Z$, et al. Discrimination of mode of action of anxiolitics using and integrated computer data bank and dynamic brain mapping (CNS effects of diazepam and lorazepam). Int Clin Psychopharmacol. 1989;4(4):273-283. 
10. Di Lazzaro V, Pilato F, Dileone M, Tonali PA, Ziemann U. Dissociated Effects of diazepam and lorazepam on short latency afferent inhibition. J Physiol. 2005;569(Pt 1):315-323.

11. Beckers T, Wagemans J, Boucart M, Giersch A. Different effects of lorazepam and diazepam on perceptual integration. Vision Res. 2001;41(17):2297-2303.

12. Giersch A, Herzog MH. Lorazepam strongly prolongs visual information processing. Neuropsychopharmacology. 2004;29(7):1386-1394.

13. Pompéia S, Manzano GM, Galduroz JC, Tufik S, Bueno OFA. Lorazepam induces an atypical dissociation of visual and auditory eventrelated potentials. J Psychopharmacol. 2003c;17(1):31-40.

14. Tang $X$, Yang L, Fishback NF, Sanford LD. Differential effects of lorazepam on sleep and activity in C57BL/6] and BALB/C] strain mice. J Sleep Res. 2009;18(3):365-373.

15. Pompéia S, Grego BH, Pradella-Hallinan M, Hachul H, Tufik S, D'Almeida $V$. Acute benzodiazepine administration induces changes in homocysteine metabolism in young healthy volunteers. Prog Neuropsychopharmacol Biol Psychiatry. 2009;33(6):933-938.

16. Hillemacher $\mathrm{T}$, Frieling $\mathrm{H}$, Bayerlein $\mathrm{K}$, Wilhelm J, Kornhuber J, Bleich S. Biological markers to predict previous alcohol withdrawal seizures: a risk assessment. J Neural Transm. 2007;114(2):151-154. 17. Hughes JR. Alcohol withdrawal seizures. Epilepsy Behav. 2009;15(2):92-97.

18. Giersch A, Boucart M, Elliott M, Vidailhet P. Atypical behavioural effects of lorazepam: clues to the design of novel therapies? Pharmacol Ther. 2010;126(1):94-108. 